УДК 658.26

\title{
Оценка эффективности работы теплолокализующих устройств
}

\author{
А. В. Лужнаская \\ Одесский национальный политехнический университет, пр. Шевченко, 1, Одеса, 65044, Украина \\ $\triangle$ e-mail: anuta.od@mail.ru
}

\begin{abstract}
Для обеспечения условия непрорывания наружного холодного воздуха в отапливаемые помещчения зданий и сооружений различного назначения, решалась задача распределения полей избыточных температур во взаимодействующих струях. Для оиенки эффективности работы теплолокализующих устройств были рассмотрены типовые завесы для различных наружных проемов и завесы с перемежаюшимися щелями. Струя, истекаюшая из типовой воздушно-тепловой завесы, подчиняется законам истечения для плоских струй, а из завесы с разрывом струи - для компактных. В ходе исследования были определены: начальная скорость истечения, действительная и относительные скорости воздушного потока, расход воздуха и тепла для всех рассматриваемых типов систем теплолокализации, в результате определена тепловая эффективность. Выполнены расчеты по определению температурного интервала зимнего наружного воздуха, при котором достигается наибольший тепловой экономический эффект от внедрения предложенного способа теплолокализации.
\end{abstract}

Ключевые слова: воздушно-тепловая завеса; плоская воздушная струя; компактная воздушная струя; начальная температура истечения; эффективный температурный интервал.

\section{Оцінка ефективності роботи теплолокализуючих пристроїв}

\section{Г. В. Лужанська}

Одеський національний політехнічний університет, пр. Шевченко, 1, Одеса, 65044, Україна

\begin{abstract}
Для забезпечення умови непроривання зовнішнього холодного повітря в опалювальні примішення будівель і споруд різного призначення, вирішувалася задача розподілу полів надлишкових температур у взаємодіючих струменях. Для оцінки ефективності роботи теплолокалізуючих пристроїв були розглянуті типові завіси для різних зовнішніх отворів $і$ завіси з переміжними щчілинами. Струмінь, щуо виходить з типової повітряно-теплової завіси, підпорядковується законам витікання для плоских струменів, а з завіси з розривом струменя - для компактних. В ході дослідження були визначені: початкова швидкість витікання, дійсна та відносні швидкості повітряного потоку, витрата повітря і тепла для всіх розглянутих типів систем теплолокалізаціi, в результаті визначена теплова ефективність. Виконані розрахунки по визначенню температурного інтервалу зимового зовнішнього повітря, при якому досягається найбільший теплової економічний ефект від впровадження запропонованого способу теплолокализации.
\end{abstract}

Ключові слова: повітряно-теплова завіса; плоский повітряний струмінь; компактний повітряний струмінь; початкова температура витікання; ефективний температурний інтервал.

DOI: http://dx.doi.org/10.15673/ret.v53i4.705

(C) The Author(s) 2017. This article is an open access publication

This work is licensed under the Creative Commons Attribution 4.0 International License (CC BY)

http://creativecommons.org/licenses/by/4.0/

\section{1 Введение}

При распределении воздушного потока, истекающего из воздуховыпускных отверстий воздушно-тепловой завесы, для обеспечения условия непрорывания наружного воздуха в помещения необходимо решить задачу распределения полей избыточной температуры во взаимодействующих струях.

Смешение при взаимодействии струй является одной из важных концепций аэродинамики вентиляции. Под классической картиной смешения воздушных струй подразумевается, что на некотором расстоянии, после их слияния, имеет место единый воздушный поток. От зоны смешения потоков до зоны установивше- гося слияния воздушного потока - вблизи его границы, можно наблюдать «противоток» или «подсос воздуха».

На практике смешение струй воздуха (не идеального газа) определяется либо по зоне, где происходит взаимодействие воздушных масс, либо по максимальной способности проникновения воздушных струй друг в друга. В любом случае область смешения струй воздушного потока начинается раньше, чем установившегося [1].

Применяя данные исследования к конструкции теплолокализующих устройств, получим, что при перемежающемся перекрывании щели воздуховыпускного отверстия взаимодействие и слияние струй происходит на начальном участке, при этом предотвращается про- 
никновение холодного наружного воздуха в отапливаемое помещение, что соответственно обеспечивает сохранение тепла в цехе.

\section{2 Основная часть}

Воздушный поток, истекающий из типовой воздушной завесы, представляет собой плоскую неизотермическую струю. Применяя к типовым завесам предлагаемую конструкцию - перекрыть воздухораспределительное щелевое отверстие в перемежающемся порядке по вертикали, получим компактную воздушную струю истекающего воздуха, которая на некотором расстоянии от источника истечения (на начальном участке развития струи), сливаясь в единый воздушный поток, образует плоскую неизотермическую струю [2].

Для определенности были рассмотрены применяемые в настоящее время типовые завесы для стандартных промышленных проемов $4 \times 4$ м в реальных условиях на примере завесы ЗТВ 1.00.000-3 (рекомендуется применять для наружных проемов 3,6×3,6 м), которые наиболее близко подходят по тепловой мощности $\mathrm{G}=40800$ кг/ч, а по расходу воздуха на завесу по расчету 39079 кг/ч. При этом оставшуюся вертикальную часть открытого незащищенного наружного проема перекроем брезентовыми шторами с прорезями, поднимающимися вверх при проезде в цех габаритного транспорта или горизонтальными складными жалюзями, автоматически поднимающимися при въезде транспорта [3].

Характеристика завесы ЗТВ 1.00.000-3: размер щели $3,6 \times 0,09$ м - площадь 0,324 м $^{2}$ с каждой стороны насадка. Это соответствует условию, что площадь щели составляет $1 / 20-1 / 30=0,05-0,03$ площади проема. При выпуске воздуха из воздуховыпускного отверстия образуется плоская горизонтальная неизотермическая струя, свойства которой исследуем по методике [4].

Относительная скорость воздушного потока, истекающего из завесы, на расстоянии, равном половине ширины наружного проема, т.е. на 2 м, которое находится на основном участке струи, равняется 0,54 .

Согласно выполненному расчету типовой завесы, расход воздуха подобранной завесы составит $\mathrm{G}=40800$ $\kappa г / ч, L=32903 \mathrm{~m}^{3} /$ ч.

Если расчет воздуха вести по требуемому расходу, то $\mathrm{L}=32903 \mathrm{~m}^{3} /$ ч (для двухсторонней завесы), расход воздуха с одной стороны - $16452 \mathrm{~m}^{3} /$, а скорость истечения при данном расходе 14,10 м/с. С учетом, что относительная скорость равна 0,54 , то действительная осевая скорость на расстоянии 2 м будет 7,62 м/с
При этом:

- расход воздуха на завесу: $\mathrm{L}=16452 \mathrm{~m}^{3} / 4, \mathrm{G}=20400$ кг/ч (для одной стороны);

- расход тепла на завесу $\mathrm{Q}_{3}=258502 \mathrm{BT}$;

- дополнительный расход тепла на подогрев врывающегося в помещение воздуха $\mathrm{Q}_{\text {доп }}=78158 \mathrm{BT}$;

- $\mathrm{Q}_{3}+\mathrm{Q}_{\text {доп }}=336661 \mathrm{BT}$.

В результате перекрытия щелевого воздухораспределительного отверстия, в перемежающемся порядке образуются плоские компактные струи, истекающие в одном параллельном направлении из щелей одинаковых размеров $0,18 \times 0,09$ м, с равными начальными скоростями, и отделенные друг от друга по вертикали расстоянием равным длине щелевого отверстия [3].

При данном истечении воздушного потока образуется компактная струя, которая на расстоянии 2 м переходит в круглую, осесимметричную [5].

Эквивалентный диаметр рассматриваемого щелевого отверстия $0,14 \mathrm{M}$.

Относительная скорость осесимметричной струи на основном участке 0,31 .

С учетом, что скорость плоской струи на расстоянии 2 м равна 7,62 м/с, то скорость истечения компактной струи будет $24,58 \mathrm{~m} / \mathrm{c}$.

Таким образом, условие выполняется, скорость истечения не превышает предельно допустимого значения истечения скорости из воздушной завесы, равной 25 $\mathrm{M} / \mathrm{c}$.

В результате уменьшения живого сечения выхода воздуха происходит слияние компактных струй в один воздушный поток [5] и скорость истечения не превышает нормируемую.

Следовательно, при перекрытии воздухораспределительного отверстия в перемежающемся порядке, общая площадь воздуховыпускной щели составит $0,162 \mathrm{~m}^{2}$ что подтверждает выполнение требуемых норм.

Необходимый расход воздуха составил (для одной стороны) $14335 \mathrm{~m}^{3 / 4}$.

При этом:

- расход воздуха на завесу: $L=14335 \mathrm{~m}^{3} / 4$, $\mathrm{G}=17775$ кг/ч ;

- расход тепла на завесу $\mathrm{Q}_{3}=224896 \mathrm{BT}$;

- дополнительный расход тепла на подогрев врывающегося в помещение воздуха $\mathrm{Q}_{\text {доп }}=67997 \mathrm{~B}$;

- $\mathrm{Q}_{3}+\mathrm{Q}_{\text {доп }}=292893$ Вт.

Таким образом, в результате проведенных исследований с целью выявления эффективности работы предлагаемого типа завесы [3], данные по расчету сведены в сравнительную таблицу 1.

Таблица 1 - Сравнение эффективности работы типовой завесы и завесыс разрывом струи для ворот размером $4 \times 4$ м

\begin{tabular}{|l|c|c|}
\hline \multicolumn{1}{|c|}{ Тип завесы } & $\begin{array}{c}\text { Типовая завеса } \\
\text { 3ТВ 1.00.000-3 }\end{array}$ & $\begin{array}{c}\text { Завеса с } \\
\text { разрывом струи }\end{array}$ \\
\hline Размер щелевого воздухораспределительного отверстия, $\mathrm{M}$ & $3,6 \times 0,09$ & $0,18 \times 0,09$ \\
\hline Площадь щелевого воздухораспределительного отверстия, $\mathrm{M}^{2}$ & 0,324 & 0,162 \\
\hline Тип истекающей струи воздуха & плоская & компактная \\
\hline Скорость истечения воздуха $\mathrm{V}_{0}, \mathrm{M} / \mathrm{c}$ & 14,10 & 24,58 \\
\hline Расход воздуха на завесы (с одной стороны) L, $\mathrm{m}^{3} / \mathrm{ч}$ & 16452 & 14335 \\
\hline Расход тепла на завесу $\mathrm{Q}_{3}, \mathrm{BT}$ & 250891 & 224896 \\
\hline Тепловая эффективность, \% & & 14 \\
\hline
\end{tabular}


Анализ полученных результатов позволяет сделать вывод, что при перекрывании щели воздуховыпускного насадка типовой воздушной завесы ЗТВ 1.00.000-3 размером 3,6×0,09 м в перемежающемся порядке отверстиями размером $0,18 \times 0,09$ м происходит уменьшение объемов подаваемого воздуха, что соответственно приводит к экономии тепловой энергии. Применение завесы ЗТВ 1.00.000-3 для стандартного проема для наружных ворот 3,6×3,6 м требуемый расход воздуха на заве- су при тех же начальных условиях будет равен около 31000 кг/ч, что составляет три четверти от ее паспортной производительности. Во избежание перерасхода тепловой энергии воздушно-тепловая завеса будет работать на 0,75 своей мощности. Перекроем воздухораспределительное отверстие в перемежающемся порядке по вертикали и выполним аналогичный расчет (температура выпуска воздуха из завесы в обоих случаях одинакова), результаты которого сведены в таблицу 2 .

Таблица 2 - Сравнение эффективности работы типовой завесы и завесы с разрывом струи для ворот размером $3,6 \times 3,6$ м

\begin{tabular}{|c|c|c|}
\hline Тип завесы & $\begin{array}{c}\text { Типовая завеса } \\
\text { 3Tв 1.00.000-3 }\end{array}$ & $\begin{array}{c}\text { Завеса с } \\
\text { разрывом струи }\end{array}$ \\
\hline Размер щелевого воздухораспределительного отверстия, м & $3,6 \times 0,09$ & $0,18 \times 0,09$ \\
\hline Площадь щелевого воздухораспределительного отверстия, м² & 0,324 & 0,162 \\
\hline Тип истекающей струи воздуха & плоская & компактная \\
\hline Относительная скорость воздуха на расстоянии $\mathrm{S}=1,8 \mathrm{M}, \bar{V}$, м/с & 0,57 & 0,33 \\
\hline Скорость воздуха на расстоянии $\mathrm{S}=1,8 \mathrm{M}, \mathrm{V}, \mathrm{m} / \mathrm{c}$ & \multicolumn{2}{|c|}{6,1} \\
\hline Скорость истечения воздуха $\mathrm{V}_{\mathrm{o}}$, м/с & 10,71 & 18,48 \\
\hline Расход воздуха на завесу (с одной стороны) L, м³/ч & 12500 & 10777 \\
\hline Расход воздуха на завесу (с двух сторон), м³/ч & 25000 & 21554 \\
\hline Количество воздуха на завесу, кг/ч & 31000 & 26727 \\
\hline Расход тепла на завесу $\mathrm{Q}_{3}, \mathrm{~B}$ т & 154670 & 133282 \\
\hline Тепловая эффективность, \% & \multicolumn{2}{|c|}{14} \\
\hline
\end{tabular}

Анализ полученных данных позволяет сделать вывод, что при устройстве тепловых завес с разрывом щели энергосберегающий эффект достигает $14 \%$ (для сравнения - в предыдущем случае - $11 \%$ ).

Затраты тепла, необходимые для эффективной работы воздушно-тепловой завесы в отопительный период для г. Одессы:

$$
\mathrm{Q}_{3}=0,28 \mathrm{G}_{3}\left(\mathrm{t}_{3}-\mathrm{t}_{\mathrm{BX}}\right)
$$

где $\mathrm{t}_{\mathrm{Bx}}$ - температура воздуха, забираемого для завесы, ${ }^{\circ} \mathrm{C}$;

$\mathrm{t}_{3}$ - температура воздуха, подаваемого для завесы, ${ }^{\circ} \mathrm{C}$; $\mathrm{G}_{3}$ - количество подаваемого воздуха завесой, кг/ч.

Результаты расчетов для стандартной типовой завесы и для предлагаемого теплолокализующего устройства с перемежающимся щелевым отверстием приведены в виде графической зависимости потребляемой тепловой мощности воздушно-тепловой завесы от изменения температуры наружного воздуха в отопительный период (рисунок 1). Анализ полученных данных показал, что тепловая эффективность предлагаемой тепловой завесы с перекрываемой щелью по сравнению с типовой завесой ЗТВ 1.00.000-3 для г. Одессы в отопительный период составит $11 \%$ при этом интервале положительных температур от $8^{\circ} \mathrm{C}$ до $0^{\circ} \mathrm{C}$.

Для оценки экономии тепловой энергии при использовании предлагаемого способа, заключенного в перекрывании в перемежающемся порядке щелевого воздухораспределительного отверстия, в различных регионах
Украины, выполним аналогичный расчет на основании [3].

Результаты приведены в виде графической зависимости потребляемой тепловой мощности воздушнотепловой завесы от изменения температуры наружного воздуха в отопительный период для рассматриваемых городов Украины (рисунок 2).

Анализ полученных зависимостей показывает, что для городов Украины с расчетной температурой наружного воздуха от $-6^{\circ} \mathrm{C}$ до $-23^{\circ} \mathrm{C}$ наиболее целесообразно по энергосберегающим технологиям принимать к установке воздушно-тепловую завесу с перекрываемой щелью. При этом наибольший тепловой экономический эффект, равный 14,5\%, достигается при температуры наружного воздуха в диапазоне от $-15^{\circ} \mathrm{C}$ до $6^{\circ} \mathrm{C}$. При этом можно констатировать, что при расчетных температурах наружного воздуха в отопительный период $-24^{\circ} \mathrm{C}$ и ниже - данная завеса не может быть использована вследствие невозможности обеспечения требуемого расхода подаваемого воздуха.

В результате проведенных исследований воздушнотепловой завесы с перекрываемым щелевым воздухораспределительным отверстием в перемежающемся порядке по вертикали, со слиянием струй в единый воздушный поток для открытых наружных проемов выявлено, что экономическая эффективность использования данного типа завесы для г. Одессы в отопительный период составляет $11 \%$.

Применяя рассматриваемую конструкцию завесы для различных городов, расположенных на территории 
Украины с расчетными температурами наружного воздуха от $-6^{\circ} \mathrm{C}$ до $-23^{\circ} \mathrm{C}$ (продолжительность отопительного периода 126-195 суток) энергосберегающий эффект достигается 14,5\% по сравнению с типовой воздушно-тепловой завесой.

При этом осуществляется замена единой плоской струи (типовая завеса) набором компактных струй (предложенный способ создания воздушно-тепловой завесы путем перекрывания щелевого отверстия по вертикали в перемежающемся порядке), которые на начальном участке образуют единую плоскую струю. Экономия тепловой энергии достигается за счет уменьшения количества подаваемого воздуха, нагретого до требуемой температуры в калориферной установке.

Q, КBT

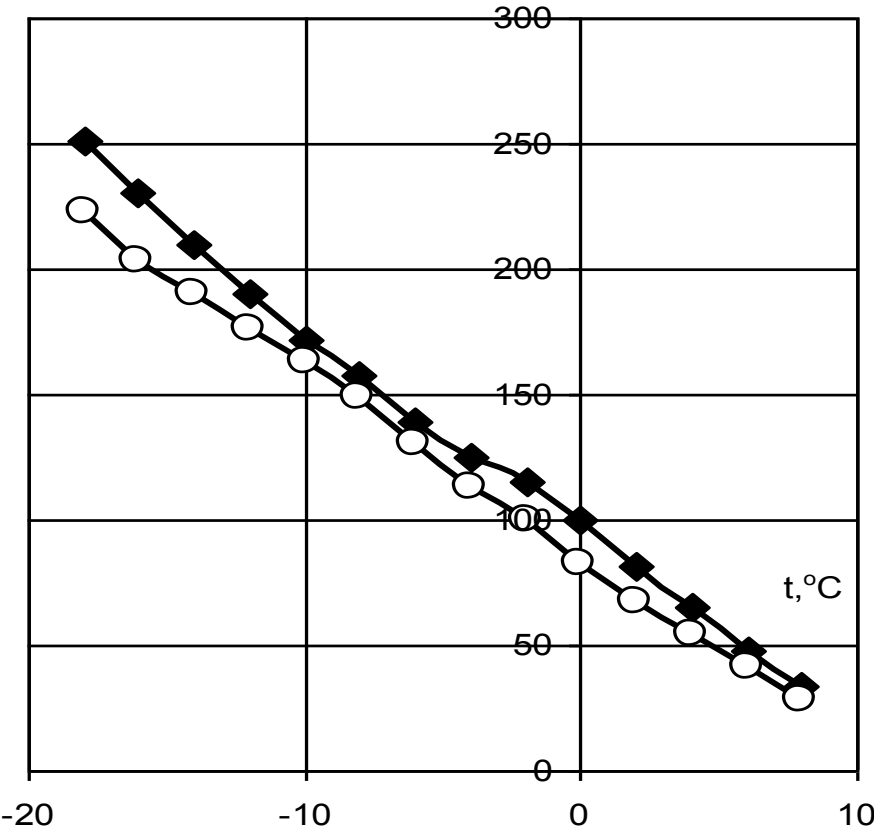

- - для типовой завесы; О - для завесы с перемежающимися щеелями.

Рисунок 1 - Расход тепловой энергии от температуры наружного воздуха:

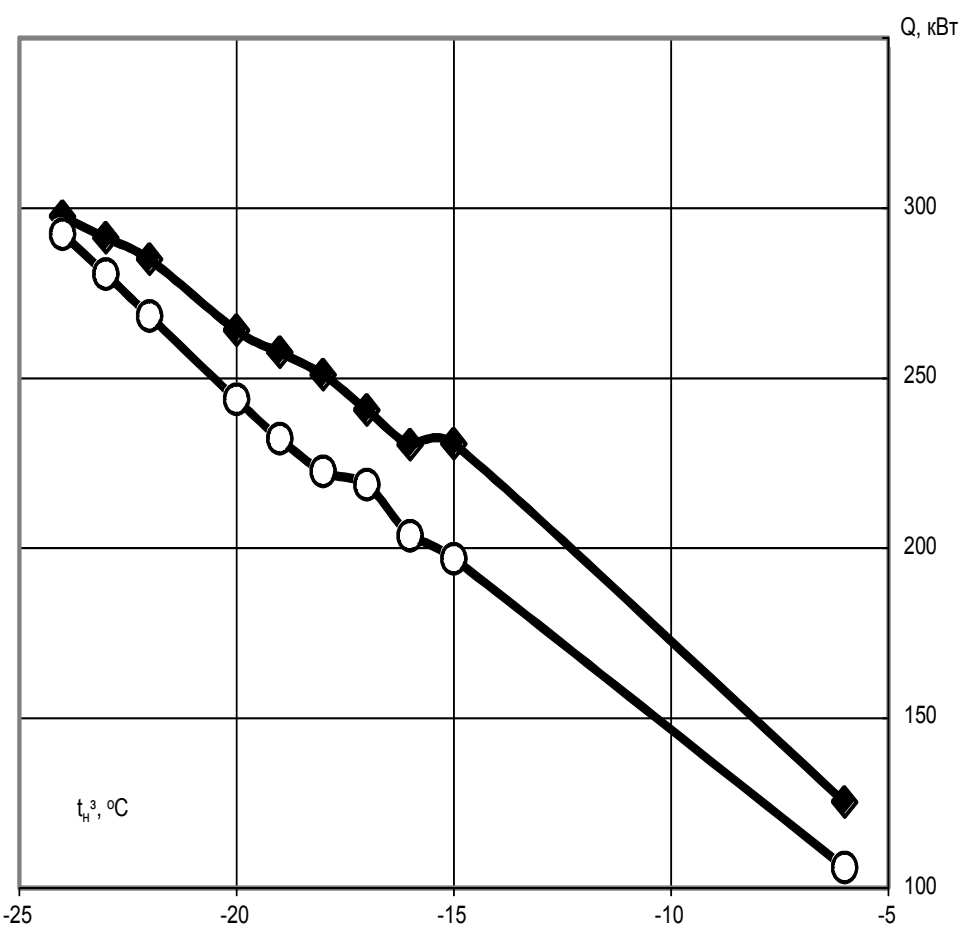

- - для типовой завесы; О - для завесы с перемежающимися щелями.

Рисунок 2- Расход тепловой энергии в различных городах Украины: 


\section{3 Выводы}

1. При сравнении типовой воздушной завесы 3ТВ.1.00.000-3 и завесы с перекрываемой щелью, тепловая экономическая эффективность последней находится в пределах 11-14\%.

2. Экономия тепла при использовании завесы с перекрываемой щелью для г. Одессы за отопительный период (температура наружного воздуха от $+8^{\circ} \mathrm{C}$ до $18^{\circ} \mathrm{C}$ ) составит в среднем $11 \%$.

3. Рекомендовано для городов Украины с расчетной температурой наружного воздуха от $-6^{\circ} \mathrm{C}$ до $23^{\circ} \mathrm{C}$ принимать к установке воздушно-тепловую завесу с перекрываемой щелью. Однако наибольший тепловой экономический эффект 14,5\% достигается при температурах наружного воздуха в диапазоне от $-15^{\circ} \mathrm{C}$ до $6^{\circ} \mathrm{C}$.

\section{Література}

1. Лужанская А.В. Энергосбережение в системах теплозащиты воздушно-тепловых завес. // Вентиляція, освітлення та теплогазопостачання: Науково-технічний збірник. - К.: КНУБА. - 2005. - №8. - С. 96-98.

2. Г.В. Лужанська, А.С.Денисова. Дослідження систем теплолокалізаціі повітряно-тепловими завісами // Холодильна техніка і технологія. Одесса:- 2016. - №6 (Том 52). - C. 25-28.

3. Лужанская А.В., Зайцев О.Н., Аэродинамика воздушно-тепловых завес в промышленных зданиях и сооружениях (монография). Научное издание к 50-ти летию НАПКС - Симферополь: НАПКС, СОНАТ 2009 184, ISBN 9668111-56-7

4. Лужанская А.В., Лужанская И.И. Теоретическое исследование температурных полей при слиянии плоских неизотермических струй. // Вісник ОДАБА. - Одеса: ОДАБА. - 2003. - №9. - С. 107-111.

5. Лужанская А.В. Исследование влияния неизотермичности плоских струй на траекторию воздушного потока. // Научно-технический сборник «Коммунальное хозяйство городов». Выпуск 53. Серия: технические науки и архитектура. Харьковская Государственная Академия городского хозяйства. Киев “Техника”, 2003. - C. 257-261.

Отримана в редакції 22.05.2017, прийнята до друку 06.06.2017

\title{
Evaluation of Thermal Increasing Devices Operation Effectiveness
}

\author{
G. V. Luzhanska \\ Odessa national polytechnic university, 1 Shevchenko av., Odessa, 65044, Ukraine \\ $\triangle$ e-mail: anuta.od@mail.ru
}

\begin{abstract}
The distribution of the air flow flowing from the air outlet air curtains, shutting off in the alternating manner vertical merging of jets in uniform air flow in their movement and interaction is one of the basic concepts of aerodynamics. To ensure that the terms of continuous external cold air in the heated space of buildings and constructions of various purpose, the problem of the field distribution of excess temperatures in interacting jets has been solved. The merging of jets in uniform air flow occurs at the initial part. To assess the effectiveness of thermal increasing devices typical for various outdoor curtain openings and curtains with intermittent cracks were considered. The stream flowing from the model air curtains, obey the laws expiry for flat jets, and from the curtain with a gap jet - for compact. In the course of the study the initial velocity, actual and relative speed of the air flow, air flow and heat for all considered types of systems of thermo regulation were identified. The calculations for the standard model of the veil and for the proposed thermo regulation device with alternating slot opening are given in the form of graphic dependency of the consumed heat output of air curtains from changes in outdoor temperature during the heating period for different cities of Ukraine.
\end{abstract}

Keywords: Air-Thermal Curtain; Flat Air Jet; Compact Air Jet; Initial Temperature Of Expiration; Energy-Efficient Temperature Range.

\section{References}

1. Luzhanska G.V. (2005) Energosberezhenie v sistemakh teplozachiti vozdushno-teplovikh zaves. Ventyliatsiia, Osvitlennia ta Teplohazopostachannia, No.8, 96-98. (in Russian).

2. Luzhanska G. V., Denysova A. E. (2016) Investigation of heat localization by using air-thermal curtains. Refrigeration Engineering and Technology, 6(52), 25-28. (in Ukrainian).

DOI: http://dx.doi.org/10.15673/ret.v52i6.470

3. Luzhanska G.V., Zaicev O.N. (2009) Aerodinamika wozdushno-teplowix zawes $w$ promishlennix zdaniyax $i$ soorujeniyax (monografia), 2009, 184 p (in Russian).
4. Luzhanska G.V., Luzhanska I.I. (2003) Teoreticheskoe issledovanie temperaturnikh polej pri slijanii ploskikh neizotermicheskikh struj. Visnyk ODABA, No.9, 107-111 (in Russian).

5. Luzhanska G.V. (2003) Issledovanie vlijanija neizotermicheskikh ploskikh struj na traektoriu vozdushnogo potoka. Kommunalnoie khoziaistvo gorodov, No.53, 257-261 (in Russian). 